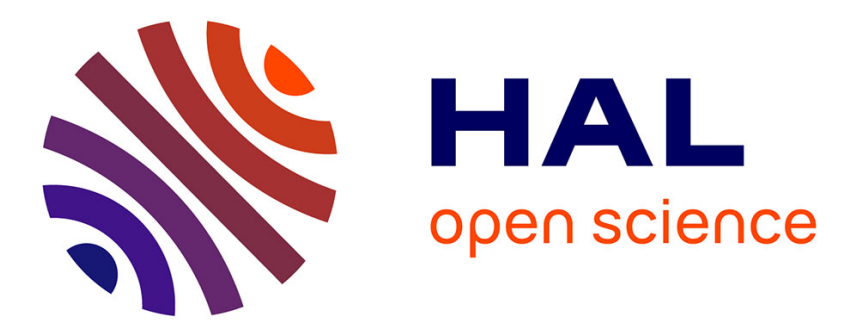

\title{
Mechanisms and kinetics of short pulse laser-induced destruction of silver-containing nanoparticles in multicomponent silicate photo-thermo-refractive glass
}

\author{
J. Lumeau, Leonid B. Glebov
}

\section{- To cite this version:}

J. Lumeau, Leonid B. Glebov. Mechanisms and kinetics of short pulse laser-induced destruction of silver-containing nanoparticles in multicomponent silicate photo-thermo-refractive glass. Applied optics, 2014, 53 (31), pp.7362-7368. 10.1364/AO.53.007362 . hal-01082033

\section{HAL Id: hal-01082033 https://hal.science/hal-01082033}

Submitted on 13 Mar 2019

HAL is a multi-disciplinary open access archive for the deposit and dissemination of scientific research documents, whether they are published or not. The documents may come from teaching and research institutions in France or abroad, or from public or private research centers.
L'archive ouverte pluridisciplinaire HAL, est destinée au dépôt et à la diffusion de documents scientifiques de niveau recherche, publiés ou non, émanant des établissements d'enseignement et de recherche français ou étrangers, des laboratoires publics ou privés. 


\title{
Mechanisms and kinetics of short pulse laser- induced destruction of silver containing nano- particles in multicomponent silicate photo- thermo-refractive glass
}

\author{
Julien Lumeau, ${ }^{1,2, *}$ and Leonid B. Glebov ${ }^{2}$ \\ ${ }_{1}^{1}$ Aix Marseille Université, CNRS, Centrale Marseille, Institut Fresnel UMR 7249, 13013 Marseille, France \\ ${ }^{2}$ CREOL, The College of Optics and Photonics, University of Central Florida, P.O. Box 162700, Orlando, Florida 32816- \\ 2700, USA \\ *Corresponding author: julien.lumeau@fresnel.fr \\ Received Month X, XXXX; revised Month X, XXXX; accepted Month X, \\ XXXX; posted Month X, XXXX (Doc. ID XXXXX); published Month X, XXXX
}

\begin{abstract}
Photo-thermo-refractive (PTR) glass is a photosensitive multi-component glass which is commercially used for the recording of volume holographic elements and finds many applications in advanced laser systems. Refractive index decrement in this glass is observed after UV exposure followed by thermal development. This procedure also causes the appearance of Ag containing particles that can be then optically bleached by using the second harmonic of a Nd:YAG laser. Despite the broad usage of this method, its mechanisms are still unclear. In this paper, a systematic study of the short pulse laser-induced destruction of Ag containing particles kinetics versus incident energy per pulse and dosage is presented. We show that no beaching of Ag containing particles occurs for energy density in laser pulses below $0.1 \mathrm{~J} / \mathrm{cm} 2$ while above $1 \mathrm{~J} / \mathrm{cm} 2$, the efficiency of bleaching saturates. Efficiency of bleaching depends on the type of particles to be bleached (Ag, AgBr...). Using a simple model of short pulse laser interaction with nano-particles embedded in glass, the temperature of the Ag containing particles reached during the laser interaction is shown to be large enough to produce complete dissipation of these particles which is expected to be the main mechanisms of short pulse laser-induced destruction of $\mathrm{Ag}$ containing particles.
\end{abstract}

OCIS codes: (5335) Photosensitive materials; (3538) Lasers, pulsed; (1030) Absorption http://dx.doi/org/10.1364/AO.99.099999

\section{Introduction}

Photo-thermo-refractive (PTR) glass is a sodium-potassiumzinc-aluminum-fluorine-bromine silicate glass doped with antimony, tin, cerium, and silver. This class of glasses, which undergo photo-thermo-induced crystallization, was invented by S.D. Stookey [1] many years ago and has been studied as a candidate for hologram writing in the last 20 years [2-5]. PTR glass exhibits a localized refractive index decrement after UVexposure and successive thermal treatment above the glass transition temperature, $\mathrm{Tg}$, which results from the crystallization of about 0.5 wt.\% sodium fluoride nano-crystals [6]. The possibility of recording phase holograms in this glass has potential for many high-tech applications, such as optical filtering [7] and spectral beam combining of high power lasers [8].

A description of the complex photo-thermo-induced crystallization mechanisms in this type of glass is given in reference [9]. The evolution of the material's nanostructure and optical properties after UV-exposure and thermal treatment are reported in several publications e.g. [6, 10-14]. Actually, it was shown in ref. [6] that the photosensitivity of PTR glass results from the precipitation of nano-sized sodium fluoride crystals within the glass matrix in the UV-exposed regions after heat treatment. A simplified proposal for photo-thermal crystallization is the following: before any thermal development of the glass, sodium, fluorine and all other ions are uniformly dissolved in the matrix and the material is totally vitreous. When PTR glass is exposed to long wavelength $\mathrm{UV}$ radiation $\lambda>250 \mathrm{~nm}$ (e.g. $\mathrm{He}-\mathrm{Cd}$ laser at $325 \mathrm{~nm}), \mathrm{Ce}^{3+}$ releases an electron and converts to holetype $\mathrm{Ce}^{4+}$ center. The released electron is then trapped by intrinsic defects of the glass matrix or dopants and impurities in the highest valence state, including silver ions dispersed in the glass matrix. Then silver ions convert to silver atoms. When a UV-exposed glass is nucleated at temperatures between 450 and $500^{\circ} \mathrm{C}$, silver atoms agglomerate and form colloidal silver particles. It was also demonstrated that silver bromide clusters form [15]. The second part of the crystallization process consists in the heterogeneous precipitation and growth of sodium fluoride crystals on top of the silver (or silver bromide) clusters. $\mathrm{NaF}$ growth is then controlled by diffusion of sodium and fluorine from the glass matrix to the crystals [14]. It is seen that the presence of $\mathrm{Ag}$ containing particles is a mandatory step in the photoinduced crystallization. Moreover, it is very well known that the appearance of silver colloidal particles will induce a plasmon resonance that will result in an induced absorption band which position and width will depend on their composition and diameter. In ref [15,16], it was shown that depending on the size distribution and on the presence of halides (bromine or chlorine for example), the position of the induced absorption band may vary from 400 to $600 \mathrm{~nm}$. Typical losses spectrum of UV-exposed $\left(4 \mathrm{~J} / \mathrm{cm}^{2}\right.$ at $\left.325 \mathrm{~nm}\right)$ and thermally developed (1 hour at $515^{\circ} \mathrm{C}$ ) 
PTR glass in the range from 300 to $1500 \mathrm{~nm}$ is shown in Fig. 1. There are several sources that contribute to the losses of PTR glass. In UV region, there is the superposition of the absorption of cerium $+\mathrm{III}$, the induced absorption of silver containing particles and the scattering while at longer wavelength, main contributions are from the induced absorption of silver containing particles and the scattering. Moreover, it was shown in ref [17], that this band can be fully optically bleached using the second harmonic of a Nd:YAG laser at $532 \mathrm{~nm}$ (Fig. 1).

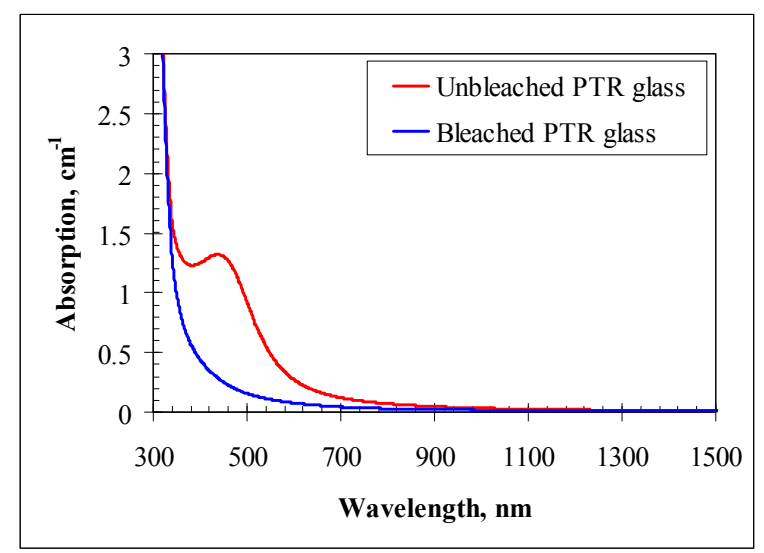

Fig. 1. Forward single pass experimental set-up for evaluating EDFA performance

Using this technique it becomes possible to extract the induced absorption band of the silver containing particles by subtracting the losses spectra before and after this optical bleaching. Fig. 2 [16] shows typical induced absorption spectrum of silver containing particles. This band is centered at $\sim 22000 \mathrm{~cm}-1$, i.e. $\sim 465 \mathrm{~nm}$ and extends from 300 to $1500 \mathrm{~nm}$.

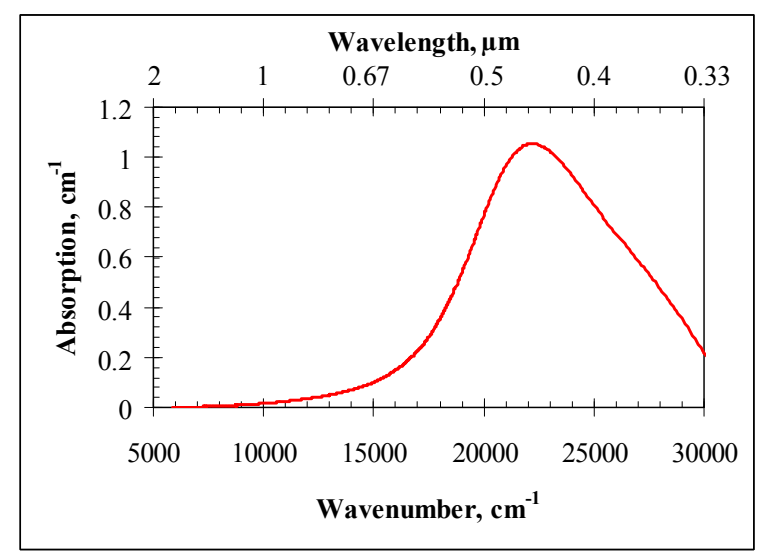

Fig. 2. Induced absorption spectrum of the silver containing particles in PTR glass obtained by subtraction of the spectra of the Fig. 1 [16].

Despite this well-known phenomenon of bleaching, the kinetics of this effect as well as its mechanisms are unclear. In this paper we investigate the kinetics of short pulse laser-induced destruction of Ag containing particles as well as the ranges of intensities which are required for getting an efficient bleaching. Then the evolution of the absorption spectra in the process of bleaching is analyzed. Finally, by analogy with the effects that were observed in solution with metallic nano-particles suspensions, a model for explaining the observed effects is proposed.

\section{Experimental and sample preparation}

\section{A. PTR glass preparation}

Samples of a photosensitive PTR glass containing $15 \mathrm{Na}_{2} \mathrm{O}-$ $5 \mathrm{ZnO}-4 \mathrm{Al}_{2} \mathrm{O}_{3}-70 \mathrm{SiO}_{2}-5 \mathrm{NaF}-1 \mathrm{KBr}-0.01 \mathrm{Ag}_{2} \mathrm{O}-0.01 \mathrm{CeO}_{2} \quad(\mathrm{~mol} \%)$ and minor amounts of $\mathrm{Sn}$ and $\mathrm{Sb}$ were used in this work as in previous studies [6,10-12]. Polished $25 \times 25 \times 5 \mathrm{~mm}^{3}$ samples were prepared from the batch. The chemical homogeneity of the samples is a critical parameter affecting crystallization properties [18], thus homogeneity was tested by the shadow method in a divergent beam of a $\mathrm{He}-\mathrm{Ne}$ laser and was quantified by measurements using an interferometer (GPI Zygo). The samples selected for this study had refractive index fluctuations of less than 40 ppm (peak-to-valley) across the aperture.

\section{B. UV-exposure and heat-treatments}

UV-exposure of samples was performed by a He-Cd laser $(4 \mathrm{~mW}$, $325 \mathrm{~nm}$ ). Samples were homogeneously exposed with dosage of $4 \mathrm{~J} / \mathrm{cm}^{2}$ by scanning several overlapped lines on the sample. Dosage was controlled with the scanning speed [10]. This dosage was chosen in order to induce an absorption band of the silver containing particles with amplitude large enough to allow its accurate measurement using a conventional dual beam spectrophotometer. The samples were then heat-treated at $480 \mathrm{and} / \mathrm{or}$ $515^{\circ} \mathrm{C}$. The samples heat-treated at $480^{\circ} \mathrm{C}$ were dropped inside hot furnace and then quenched at the end of each thermal treatment in order to control the thermal treatment duration with precision better than 1 minute and to allow performing short thermal treatment. Samples heat-treated at $515^{\circ} \mathrm{C}$ were heated from room temperature to $515^{\circ} \mathrm{C}$ at rate of about $20 \mathrm{~K} / \mathrm{minutes}$ and then cooled down to room temperature, in the furnace following the natural decrease of the furnace temperature (about $2.5 \mathrm{~K} / \mathrm{min}$ ). Finally, in order to remove any incipient crystallization on surfaces, each sample was ground and re-polished with flatness better than $N / 2$ at $633 \mathrm{~nm}$.

\section{Spectra measurements}

Transmission spectra were measured using a Perkin Elmer Lambda 950 spectro-photometer in the range from 200 to $1700 \mathrm{~nm}$. Then the spectral dependence of the losses coefficient was calculated by subtracting from the transmission spectra, the reflection spectrum of PTR glass that was calculated from the measured refractive index dispersion curve [19]. The absolute precision of such spectro-photometric measurement being limited to about $2.10^{-2} \mathrm{~cm}^{-1}$ i.e. about one order of magnitude larger than its relative precision, each curve was calibrated. To achieve, precise measurement of the transmission and the reflection at $1085 \mathrm{~nm}$ was carried out on each sample by photometric measurement using an $\mathrm{Yb}$ fiber laser. Then, losses were calculated at this wavelength, with precision of $10^{-3} \mathrm{~cm}^{-1}$ and all spectra were stitched to the measured value of losses at $1085 \mathrm{~nm}$. Using this technique, the absolute precision of each spectrum was improved to $10^{-3} \mathrm{~cm}^{-1}$. 
3. Kinetics of short pulse laser-induced destruction of $\mathrm{Ag}$ containing particles in UV-exposed and thermally developed PTR glass

A Evolution of the transmission at $532 \mathrm{~nm}$ in the process of bleaching

The simplest method that can be implemented for studying the efficiency of bleaching consists in measuring the evolution of the light coming from the second harmonic of a Nd:YAG laser and transmitted through the glass sample being bleached as a function of the dosage of bleaching. The setup used to perform this measurement is shown in Fig. 3.

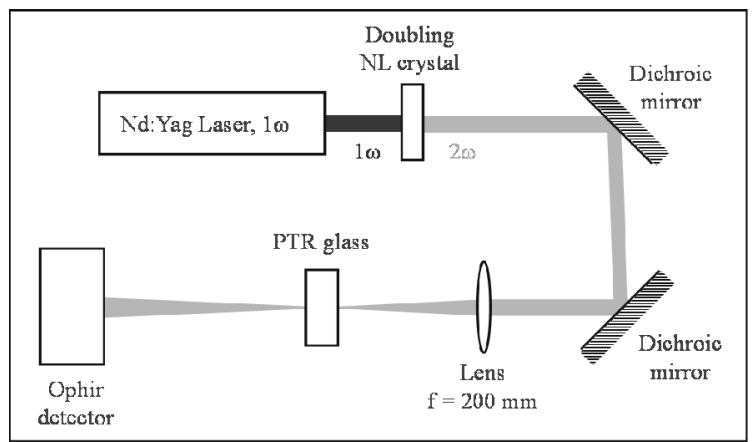

Fig. 3. Scheme of the setup used for studying the kinetics and mechanisms of optical bleaching of silver containing particles in PTR glass.

Beam from the second harmonic of a Continuum Minilite $\mathrm{Nd}$ :YAG laser at $532 \mathrm{~nm}$ was focused with a $200 \mathrm{~mm}$ lens and the sample to be bleached was placed after the focal plane of the lens such as the beam diameter was equal to $1 \mathrm{~mm}$ at $1 / \mathrm{e}^{2}$. After the sample, an Ophir detector was added in order to measure the evolution of the transmitted energy as a function of time. The energy per pulse was varied from 0.36 to $2.15 \mathrm{~J} / \mathrm{cm}^{2}$. Pulse duration was equal to $\sim 7 \mathrm{~ns}$ and repetition rate was equal to $15 \mathrm{~Hz}$. Using these parameters, beam intensity and dosage were be recalculated. Dosages from 100 to $800 \mathrm{~J} / \mathrm{cm}^{2}$ were used. Fig. 4 shows the evolution of the transmission versus dosage for different energy per pulse in a PTR glass sample that was UVexposed with a dosage of $4 \mathrm{~J} / \mathrm{cm}^{2}$, nucleated for 100 minutes at $485^{\circ} \mathrm{C}$ and finally thermally developed for 1 hour at $515^{\circ} \mathrm{C}$.

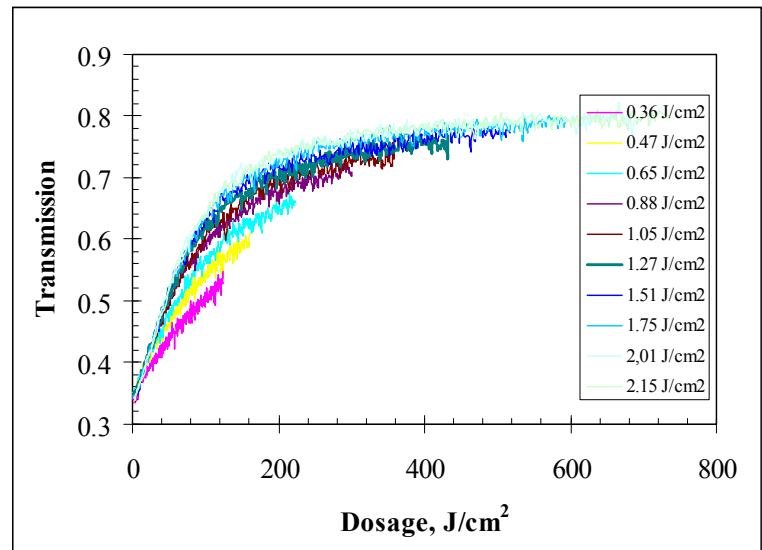

Fig. 4. Evolution of the Nd:YAG laser power transmitted through the PTR glass being bleached as a function of the dosage of exposure for different incident energies per pulse.
It is seen that the higher the energy per pulse, the steeper the slope at dosage is equal to 0 . It is also seen that at energy per pulse exceeding $1 \mathrm{~J} / \mathrm{cm}^{2}$, the slope at dosage equals to 0 tends to saturate and all curves tend to overlap. In order to quantify these findings, each curve of the dependence of the transmission (T(D)) on dosage (D) was fitted with hyperbolic functions with the form:

$$
T(D)=\frac{\alpha D}{D+k}
$$

Where $\alpha$ is the transmission after complete bleaching. Due to the level of scattering at $532 \mathrm{~nm}$, the final transmission after complete bleaching was equal to $86 \%$, meaning that the value of a was fixed to 0.86 (Fig. 5). The only remaining fitting parameter was the parameter $\mathrm{k}$, characteristic of the bleaching efficiency, the smaller $\mathrm{k}$, the higher the efficiency.

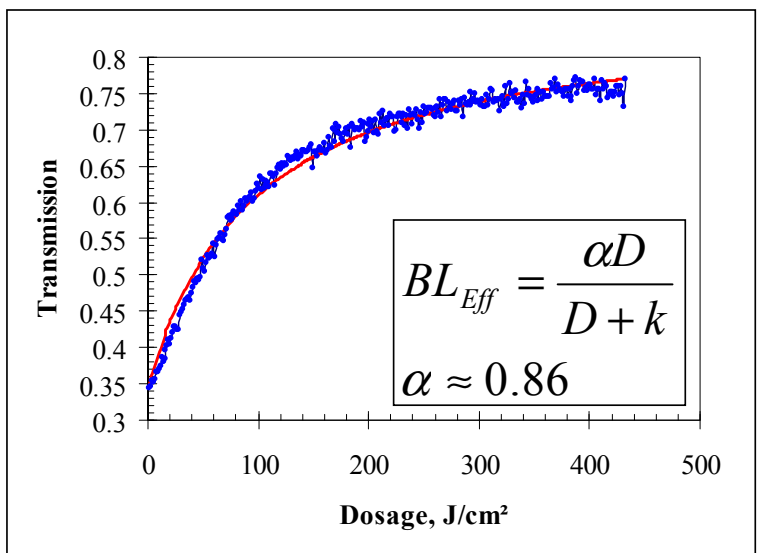

Fig. 5. Evolution of the Nd:YAG laser power transmitted through the PTR glass being bleached as a function of the dosage of exposure for an energy per pulse of $1.05 \mathrm{~J} / \mathrm{cm}^{2}$ and its fit using an hyperbolic function.

Finally, the dependence of the parameter $\mathrm{k}$ on the energy per pulse was plotted in Fig. 6. The parameter $\mathrm{k}$ decreases quickly when energy per pulse is lower than $1 \mathrm{~J} / \mathrm{cm}^{2}$ and then tends to saturate when the energy per pulse exceeds $1 \mathrm{~J} / \mathrm{cm}^{2}$. No data were taken above $2 \mathrm{~J} / \mathrm{cm}^{2}$ as the probability of surface damage or bulk damage where platinum inclusions can be found increases. Such energy per pulse dependence reflects a non-linear process but cannot be associated with any multi-photon absorption process as increasing the energy per pulse should result in an increase of the bleaching efficiency.

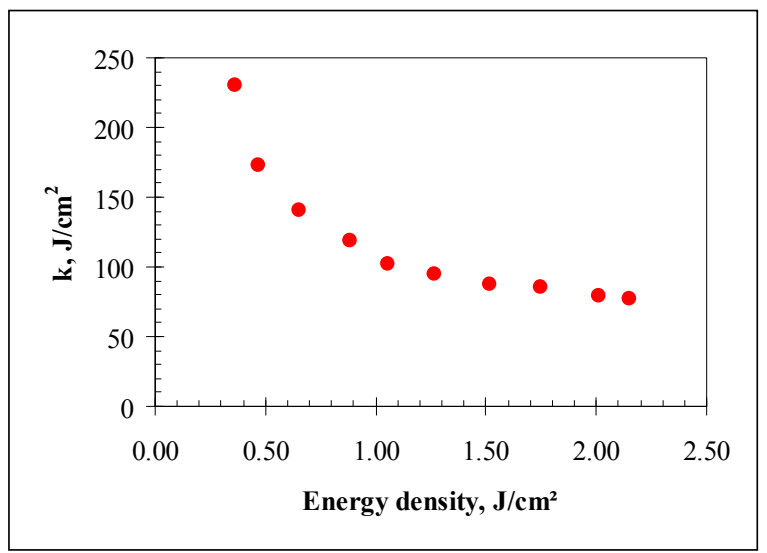

Fig. 6. Evolution of the $\mathrm{k}$ parameter of the hyperbolic function used to fit the curves of the Fig. 4. 


\section{B. Evolution of the losses spectra in the process of bleaching}

In order to gain some insights on the mechanisms of bleaching, the evolution of the losses spectra was measured in the process of bleaching. The same exposure station at $532 \mathrm{~nm}$ as the one in Fig. 3 was used to perform the bleaching. PTR glass samples similar to the one used in the $532 \mathrm{~nm}$-transmission experiment were used for this experiment, i.e. samples were UV-exposed with a dosage of $4 \mathrm{~J} / \mathrm{cm}^{2}$, nucleated and finally thermally developed for 1 hour at $515^{\circ} \mathrm{C}$. Dosage was increased by increasing the number of $532 \mathrm{~nm}$-pulses going through the PTR glass sample and spectra were measured after $532 \mathrm{~nm}$ exposure at different dosages and for different energy density per pulse. In order to study the kinetics of the silver containing particles disappearance, the bleaching efficiency $(n(B L=i))$ was then calculated after a number of bleaching (BL) equal to i using the equation (2):

$$
\eta(B L=i)=1-\frac{\operatorname{Max}_{\lambda}[L(\lambda, B L=i)-L(\lambda, B L=N)]}{\operatorname{Max}_{\lambda}[L(\lambda, B L=0)-L(\lambda, B L=N)]}
$$

Where $\mathrm{L}(\lambda, \mathrm{BL}=\mathrm{i})$ is evolution of the losses coefficient in the range [400-500] $\mathrm{nm}$ after a number of bleaching equal to $\mathrm{i}, \mathrm{L}(\lambda, \mathrm{BL}=0)$ is evolution of the losses coefficient in the range [400-500] $\mathrm{nm}$ before bleaching and $\mathrm{L}(\lambda, \mathrm{BL}=\mathrm{N})$ is evolution of the losses coefficient in the range [400-500] nm after complete bleaching. Max represents the maximum of the function between brackets. The typical evolution of the bleaching efficiency versus the $532 \mathrm{~nm}$ dosage for $1.05 \mathrm{~J} / \mathrm{cm}^{2}$ is shown in Fig. 7 .

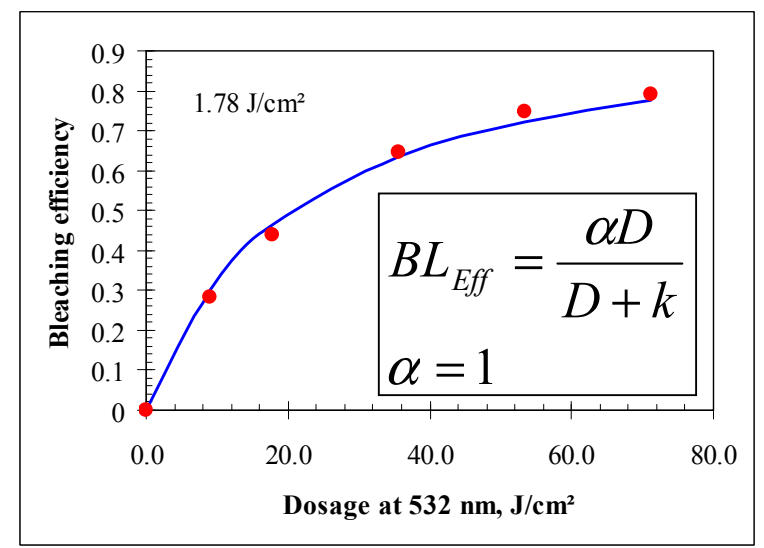

Fig. 7. Evolution of the amplitude at maximum of the silver containing particles induced absorption band that was bleached using the second harmonic of a Nd:YAG laser with an energy per pulse of $1.05 \mathrm{~J} / \mathrm{cm}^{2}$ and its fit using an hyperbolic function.

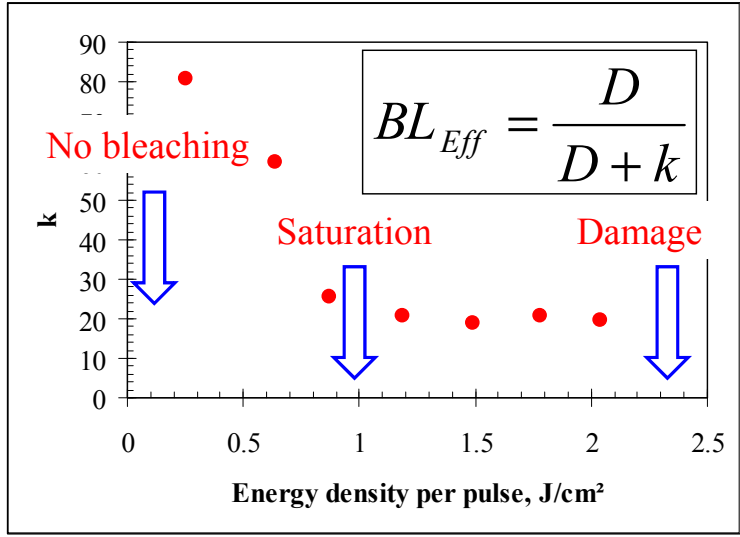

Fig. 8. Evolution of the $\mathrm{k}$ parameter of the hyperbolic function used to fit the curves similar of the Fig. 7 and obtained for different energy per pulse.

Similar measurements were carried out in samples exposed with different energy per pulse at $532 \mathrm{~nm}$ and then each curve was fitted with an hyperbolic function similar to the one of equation (1) but with a equal to 1 . Fig. 8 shows the dependence of the $\mathrm{k}$ parameter on the energy per pulse. As expected, the Fig. 8 exhibits a similar behavior as the one that was observed in Fig. 6 meaning that the features that were seen at a single wavelength are valid for the whole spectrum of silver containing particles absorption band and that saturation of the bleaching efficiency above $1 \mathrm{~J} / \mathrm{cm}^{2}$ is not a spectrally localized feature but an overall one.

\section{Kinetics of optical spectra in UV-exposed and thermally developed PTR glass}

It was seen in the previous sections that bleaching of the silver containing particles is an overall effect that results in a decrease of the whole silver containing particles absorption band but until now, the specific properties of this effect such as possible distortions of the shape of the spectra during the process of bleaching of UV-exposed and thermally developed PTR glass were not studied. UV-exposed and nucleated samples (not heattreated to promote crystals growth) were used to perform this study. These samples are very attractive because they do not present any significant scattering and because they can show very specific features. It was shown in Ref. [15-16] that the structure of the silver containing particles evolves significantly during the process of nucleation. It was also shown that the spectra of silver containing particles can be perfectly fitted using 4 Gaussian bands, 2 of them presenting a long wavelength exponential Urbach tail. Parameters of these bands are summarized in Tab. 1 and 2. Each band was associated with a different kind of particle, i.e. hole center, silver particle, silver bromide particle and a complex silver bromide particle tentatively associated with a silver bromide particle surrounded with a silver shell. Using such as decomposition, it was demonstrated that the structure of the silver containing particles absorption band of samples nucleated for 5 minutes at $485^{\circ} \mathrm{C}$ is the superposition of the bands of hole centers, silver and silver bromide particles, all bands having almost the same amplitude, while the structure of the silver containing particles absorption band of samples nucleated for 100 minutes at $485^{\circ} \mathrm{C}$ is composed with the bands of hole centers, silver bromide particles and silver bromide particles with silver shell, the first and third having similar amplitudes and the second one having twice larger 
amplitude. Using such samples, it becomes possible to separate the kinetics of bleaching of each particle as well as to reveal some aspects of the bleaching mechanisms.

Tab. 1. Parameters of the Gaussian bands used for decomposing the silver containing induced absorption band in PTR glass

\begin{tabular}{ccccc}
\hline & $\mathrm{G} 4$ & $\mathrm{G} 3$ & $\mathrm{G} 2$ & $\mathrm{G} 1$ \\
\hline $\mathrm{\sigma}_{\mathrm{i}}{ }^{0}$ & 26575 & 24275 & 22000 & 19500 \\
$\Delta \circ \mathrm{i}$ & 3465 & 2055 & 3200 & 2800 \\
$\lambda_{\mathrm{i}}{ }^{0}$ & 376 & 412 & 455 & 613 \\
Origin & Hole & $\mathrm{Ag}$ & $\mathrm{AgBr}$ & $\mathrm{Ag} / \mathrm{AgBr}$
\end{tabular}

Tab. 2. Parameters of the exponential tails used for decomposing the silver containing induced absorption band in PTR glass

\begin{tabular}{ccc}
\hline & G4 & G3 \\
\hline$\alpha_{i}$ & 8 & 7.2 \\
oi & 20040 & 18051 \\
$\alpha_{i} / \sigma i$ & $4 \times 10^{-4}$ & $4 \times 10^{-4}$
\end{tabular}

PTR glass samples were exposed at $325 \mathrm{~nm}$ with dosage of $4 / \mathrm{cm}^{2}$ and nucleated for 5 and 100 minutes at $485^{\circ} \mathrm{C}$. Samples were bleached using the second harmonic a of Nd:YAG laser and bleaching dosage was linearly increased from 1 to 60 a.u. in the samples nucleated for 5 minutes at $485^{\circ} \mathrm{C}$ while dosage was increase from 1 to 30 a.u. in the samples nucleated for 100 minutes at $485^{\circ} \mathrm{C}$. However, the exact definition of the bleaching dosage could not be obtained due to the fact that in order to increase the measurement aperture and the precision of the measurement, the sample was scanned within the beam of the $532 \mathrm{~nm}$-laser with a speed of $2 \mathrm{~mm} / \mathrm{s}$ and an energy per pulse of $1 \mathrm{~J} / \mathrm{cm}^{2}$. However, the relative increase of the dosage could be obtained due to the fact that bleaching procedure was kept constant throughout the experiment. Spectra were measured after some given dosages (Fig. 9 and 10). In case of the samples nucleated for 5 minutes at $485^{\circ} \mathrm{C}$, one can see that the maximum of the band of silver containing particles tends to shift towards larger wavelength during the beginning of the bleaching process and then tends to shift back.

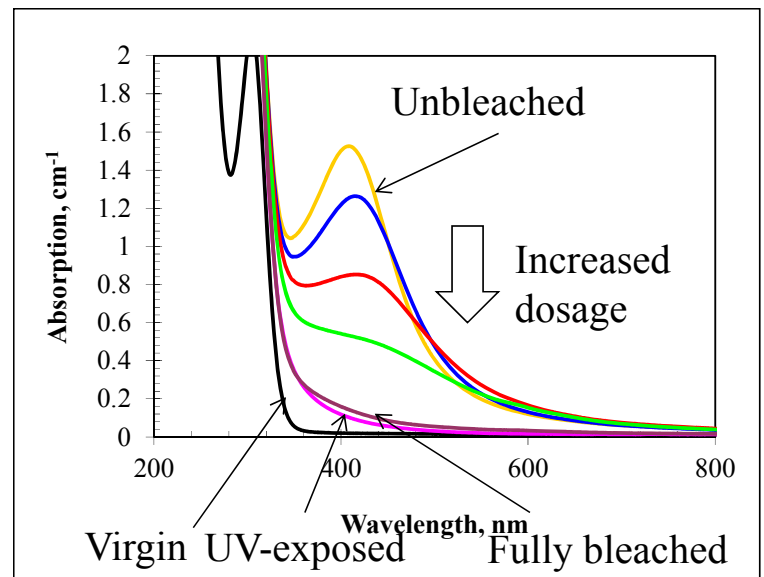

Fig. 9. Evolution of the absorption spectra of a sample nucleated for 5 minutes at $485^{\circ} \mathrm{C}$ in the process of bleaching.

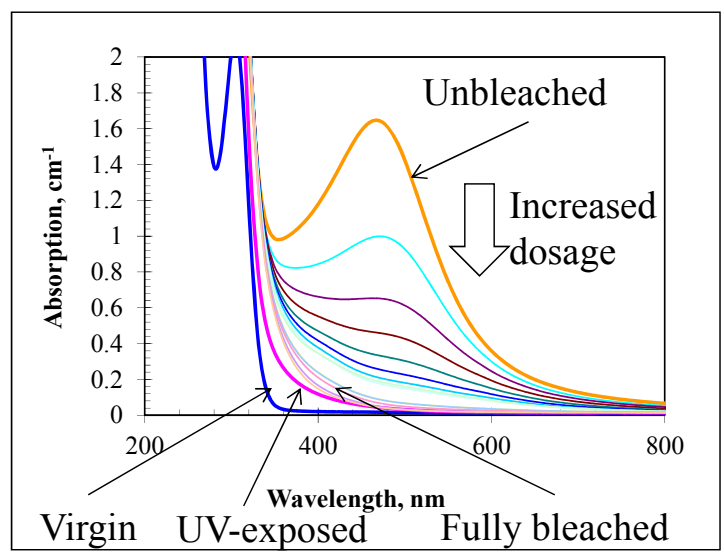

Fig. 10. Evolution of the absorption spectra of a sample nucleated for 100 minutes at $485^{\circ} \mathrm{C}$ in the process of bleaching.

Further analysis was obtained by applying a similar strategy as the one presented in Refs. [15-16]. Each induced absorption spectrum of silver containing particles was decomposed into the sum of Gaussian functions with a precision of a few percent using the model of the Ref. [15-16] and the evolution of the amplitude of each band was plotted as a function of dosage (Figs 11 and 12). The extracted amplitude of each of the silver containing particles is non-monotonously decreasing when dosage increases. More precisely, the observed evolution of each of the silver containing particles absorption band is similar to the one that was shown in the process of nucleation of PTR glass [15-16]. Therefore, while the main effect of the bleaching is an overall decrease of the volume fraction of the silver containing particles and therefore a decrease of the overall induced absorption band, additional effect appear in parallel such as the appearance of new particles.

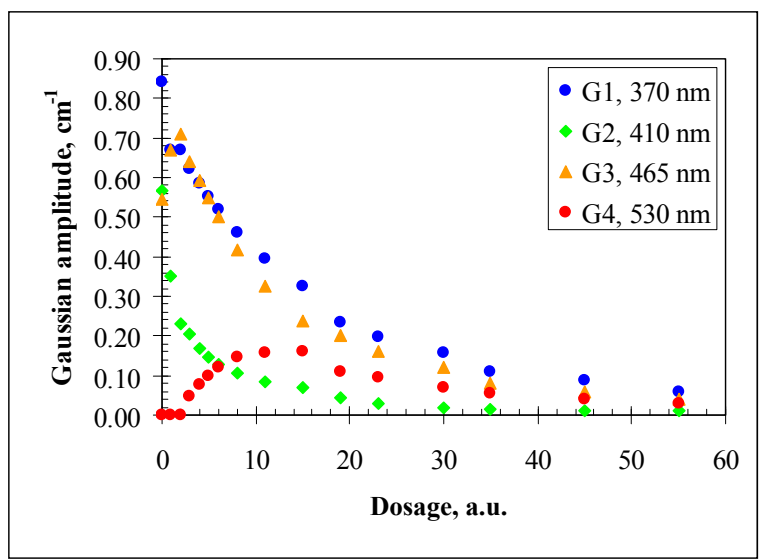

Fig. 11. Evolution of the amplitude of each of the 4 Gaussian bands used to fit the absorption spectra of a sample nucleated for 5 minutes at $485^{\circ} \mathrm{C}$ in the process of bleaching shown in Fig. 9. 


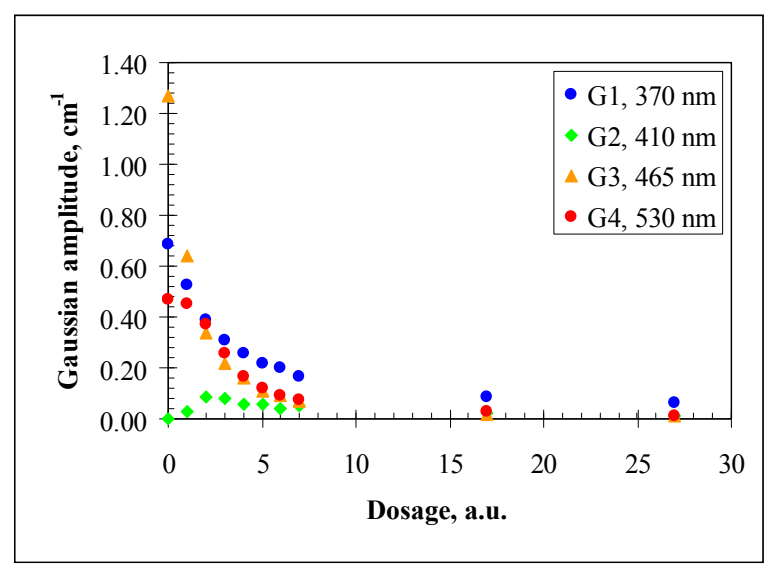

Fig. 12. Evolution of the amplitude of each of the 4 Gaussian bands used to fit the absorption spectra of a sample nucleated for 100 minutes at $485^{\circ} \mathrm{C}$ in the process of bleaching shown in Fig. 10.

\section{Analysis of the possible mechanisms of bleaching of silver containing particles}

The destruction of metallic nano-particles has already been studied in the past. There are numerous publication describing the mechanisms of bleaching of silver nanoparticles, their photodestruction, photofragmentation, and photoionization when those one are dispersed in liquids [20-27]. It was demonstrated that using nanosecond or femtosecond lasers, it is possible to evaporate the particles such as they are completely dissipated inside the liquid or to change its size and shape and associated Plasmon resonance properties. Similar efficiency curves were also measured [22]. In addition, the destruction of metallic nanoparticles in glass by short pulse laser was thoroughly studied by the laser damage community 10 years ago as the presence of metallic nano-particles such as platinum was shown the be one of the causes of laser damage in optical glass. In one of these studies [28] a simple model of such effect was developed and applied to nanoparticles of gold dispersed in a glass matrix. It was shown that the energy absorbed by one particle is:

$$
E_{p}=F \pi R^{2}
$$

While the energy for vaporization of one particle is:

$$
E_{c r}=C \rho V\left(T_{\text {boiling }}-293 K\right)+\left(H_{\text {fusion }}+H_{\text {vap }}\right) V
$$

Using induced absorption spectra of silver containing particles it is possible to estimate an approximate value of the average size of silver particles, $<\mathrm{d}>$ :

$$
<d>=\frac{v_{F}}{2 \pi c} \times \frac{\lambda^{2}}{\Delta \lambda}
$$

By evaluating the wavelength of the maximum absorption peak $(\lambda)$ and its full width at half maximum $(\Delta \lambda) ;{ }_{\mathrm{vF}}$ being the Fermi velocity of electrons in bulk metal (silver $=1.39 \times 108 \mathrm{~cm} / \mathrm{s}$ ), it is possible to calculate the size of silver containing particles (Tab. 3).

Tab. 3. Calculation of the average radius of the silver containing particles based on the plasmon resonance theory.

\begin{tabular}{cccc}
\hline Element & $\lambda, \mathrm{nm}$ & $\Delta \lambda, \mathrm{nm}$ & $<\mathrm{r}>, \mathrm{m}$ \\
\hline $\mathrm{\sigma}_{\mathrm{i}}^{0}$ & 412 & 58 & $2.2 \times 10^{-9}$ \\
$\Delta \mathrm{\sigma i}^{\mathrm{i}}$ & 454 & 111 & $1.4 \times 10^{-9}$ \\
$\lambda_{\mathrm{i}}{ }^{0}$ & 513 & 124 & $1.6 \times 10^{-9}$
\end{tabular}

Using this theory, $<\mathrm{d}>$ was estimated to be $\sim 20$ Angstrom. Using this value, it comes that the average energy absorbed by a $1 \mathrm{~nm}$ radius particle illuminated by a $1 \mathrm{~J} / \mathrm{cm}^{2}$ beam is equal to $\sim 1.3 \times 10^{-15} \mathrm{~J}$. The energy required for vaporizing silver particles is equal to $\sim 2.5 \times 10^{-16} \mathrm{~J}$ and the energy required for vaporizing silver bromide particles is equal to $\sim 7 \times 10^{-17} \mathrm{~J}$. These data demonstrate that the average absorbed energy is several times larger than the one required for vaporizing any silver containing particles in PTR glass and that bleaching is a thermo-optical process. One must however keep in mind that the huge increase of temperature happens in the particle, but not in the surrounding glass such as it appears a very large gradient of temperature at the interface between the particle and the glass. Absorption of the pulse occurs during a few nanoseconds. Then it occurs a very fast cooling of the particle due to the diffusion of the heat towards the cold glass matrix that prevents the particle from being destroyed in one pulse. These data demonstrate that bleaching is not a pure optical effect but a thermo-optical process, which also explains the evolution that was observed in Figs. 9 to 12. Actually, the very high amount of energy associated with the absorption of the pulse by the particles results in an increase of the local temperature of the particle that is analogous to a conventional heat-treatment in electrical furnace and that allows a thermal modification of the particles, analogous to that was observed in the process of nucleation in PTR glass [15-16]. The bleaching process is therefore a thermo-optical process which consists in two concurrent processes happening during the pulse duration and a short duration after: while outer part of the silver containing particles can diffuse through the glass matrix and produce a partial destruction of the particles, the inner part of the particles has enough energy to produce a conversion of the particles similar to the one observed during the process of bleaching.

\section{Conclusion}

Kinetics and mechanisms of bleaching of the absorption band of silver containing particles by the second harmonic of a Nd:YAG laser was studied. The process of bleaching is a non-linear process as it occurs above an energy density threshold estimated to be around $\sim 0.1 \mathrm{~J} / \mathrm{cm}^{2}$. Efficiency of bleaching is increasing and then saturates when energy density reaches $\sim 1 \mathrm{~J} / \mathrm{cm} 2$ until reaching damage. Optical bleaching of silver containing nanoparticles is a thermo-optical process based on the gradual dissipation of these particles as the number of pulses is increased. Finally, temperature increase during the process of bleaching has a similar impact as heating up the PTR glass to high temperature, i.e. it is continuing the process of nucleation of the silver containing particles

\section{Acknowledgements:}

This work was supported by DARPA ADHELS project. The authors want to thank Mrs Larissa Glebova and Karima Chamma for providing and preparing the PTR glass samples used in these experiments. Julien Lumeau wants also to thank Mr. Vadim Smirnov for the very fruitful discussions.

\section{References}

[1] S.D. Stookey, "Photosensitive Glass," Indust. Eng. Chem. 41 (1949) 856. 
[2] V.A. Borgman, L.B. Glebov, N.V. Nikonorov, G.T. Petrovskii, V.V. Savvin and A.D. Tsvetkov, "Photo-thermal refractive effect in silicate glasses," Sov. Phys. Dokl., 34 (1989) 1011-1013.

[3]. O. M. Efimov, L. B. Glebov, L. N. Glebova, K. C. Richardson, and V. I. Smirnov, "High-efficiency Bragg gratings in photothermorefractive glass," Appl. Opt. 38, 619-627 (1999).

[4] O.M. Efimov, L.B. Glebov, S. Papernov and A.W. Schmid, "Laser-induced damage of photo-thermo-refractive glasses for optical-holographic-element writing," Laser-Induced Damage in Optical Materials, Proc. SPIE 3578, 554-575 (1999).

[5] O.M. Efimov, L.B. Glebov and V.I. Smirnov, "High-frequency Bragg gratings in a photothermorefractive glass," Opt. Lett. 23 1693-1695 (2000).

[6] T. Cardinal, O.M. Efimov, H.G. Francois-Saint-Cyr, L.B. Glebov, L.N. Glebova and V.I. Smirnov, "Comparative study of photo-induced variations of X-ray diffraction and refractive index in photo-thermo-refractive glass," Journal of Non-Crystalline Solids 325 275-281 (2003)

[7] L.B. Glebov, V.I. Smirnov, C.M. Stickley and I.V. Ciapurin, "New approach to robust optics for HEL systems," in Laser Weapons Technology III W.E. Tompson and P.H. Merritt, Editors, Proceedings of SPIE 4724, 101-109 (2002).

[8] L.B. Glebov, "Photosensitive holographic glass-new approach to creation of high power lasers," Phys. Chem. Glasses: Eur. J. Glass Sci. Technol. B 48, 123-128 (2007).

[9] D. Stookey, G.H. Beall and J.E. Pierson, "Full-color Photosensitive Glass," J. Appl. Phys. 49, 5114-5213 (1978).

[10] O.M. Efimov, L.B. Glebov and H.P. Andre, "Measurement of the Induced Refractive Index in a Photothermorefractive Glass by a Liquid-Cell Shearing Interferometer," Appl. Optics, 41 18641871 (2002).

[11] L.B. Glebov and L. Glebova, "Swelling of photo-thermorefractive glass resulted from thermal development," Glass Science and Technology 75 C2, 294-297 (2002).

[12] L. Glebov, L. Glebova and V. Tsechomskii, and V. Golubkov, "Study of structural transformations in photo-thermo-refractive glass by SAXS and XRD," Proceedings of XX International Congress on Glass. Kyoto, Japan, September 2004.

[13] M. Hass, J. W. Davisson, H. B. Rosenstock and J. Babiskin, Applied Optics Vol. 14, No. 5, 1128-1130 (1975).

[14] L.B. Glebov, Volume hologram "recording in inorganic glasses," Glass Science and Technology 75 C1, 73-90, (2002).

[15] J. Lumeau, L. Glebova and L.B. Glebov, "Evolution of Absorption Spectra in the Process of Nucleation in PhotoThermo-Refractive Glass," Advanced Materials Research, 39-40, 395 - 398 (2008).

[16] J. Lumeau, L. Glebova, L. Glebov, "Absorption and scattering in photo-thermo-refractive glass induced by UV exposure and thermal development", Optical Materials 36, 621627 (2014).

[17] L.B. Glebov and V.I. Smirnov, "Interaction of photo-thermorefractive glass with nanosecond pulses at $532 \mathrm{~nm}$," LaserInduced Damage in Optical Materials, Proceedings of SPIE 5273, 396-401 (2004).

[18] J. Lumeau, A. Sinitskiy, L.N. Glebova, L.B. Glebov and E.D. Zanotto, "Method to assess the homogeneity of photosensitive glasses: application to photo-thermo-refractive glass", Journal of Non Crystalline Solids 355, 1760-1768 (2009).

[19] J. Lumeau and L.B. Glebov, "Refractive index measurements in photo-thermo-refractive glass at different stages of hologram fabrication", 8th Pacific Rim Conference on Ceramic and Glass Technology (PACRIM 8) (Vancouver, British
Columbia, Canada), paper PACRIM8-S25-P205-2009, June 2009.

[20] Hideaki Kurita, Akinori Takami, and Seiichiro Kodaa, "Size reduction of gold particles in aqueous solution by pulsed laser irradiation”, Appl. Phys. Lett. 72 (7), 789-791 (1998).

[21] S. Link, C. Burda, M. B. Mohamed, B. Nikoobakht, and M. A. El-Sayed, "Laser Photothermal Melting and Fragmentation of Gold Nanorods: Energy and Laser Pulse-Width Dependence”, J. Phys. Chem. A 103 (9), 1165-1170 (1999).

[22] Akinori Takami, Hideaki Kurita, and Seiichiro Koda, "LaserInduced Size Reduction of Noble Metal Particles”, J. Phys. Chem. B 103, 1226-1232 (1999).

[23] Takeshi Tsuji, Norihisa Watanabe, Masaharu Tsuji, Laser induced morphology change of silver colloids: formation of nanosize wires, Applied Surface Science Volume 211, Issues 1-4, 30 April 2003, Pages 189-193

[24] Rongchao Jin, YunWei Cao, Chad A. Mirkin, K. L. Kelly, George C. Schatz, J. G. Zheng, Photoinduced Conversion of Silver Nanospheres to Nanoprisms, Science 30 November 2001, Vol. 294 no. 5548 pp. 1901-1903

[25] Susie Eustis, Galina Krylova, Anna Eremenko, Natalie Smirnova, Alexander W. Schill and Mostafa El-Sayed, Growth and fragmentation of silver nanoparticles in their synthesis with a fs laser and CW light by photo-sensitization with benzophenone, Photochem. Photobiol. Sci., 2005, 4, 154-159

[26] Y. Badr, M.G. Abd El Wahed, M.A. Mahmoud, On 308 nm photofragmentation of the silver nanoparticles, Applied Surface Science, Volume 253, Issue 5, 30 December 2006, Pages 25022507

[27] Prashant V. Kamat, Mark Flumiani, and Gregory V. Hartland, Picosecond Dynamics of Silver Nanoclusters. Photoejection of Electrons and Fragmentation, J. Phys. Chem. B, 1998, 102 (17), pp 3123-3128

[28] S. Papernova and A. W. Schmid, "Correlations between embedded single gold nanoparticles in $\mathrm{SiO} 2$ thin film and nanoscale crater formation induced by pulsed-laser radiation”, J. Appl. Phys. 92 (10), 5720-5728 (2002). 